\title{
The impact of integrated team care taught using a live NHS contract on the educational experience of final year dental students
}

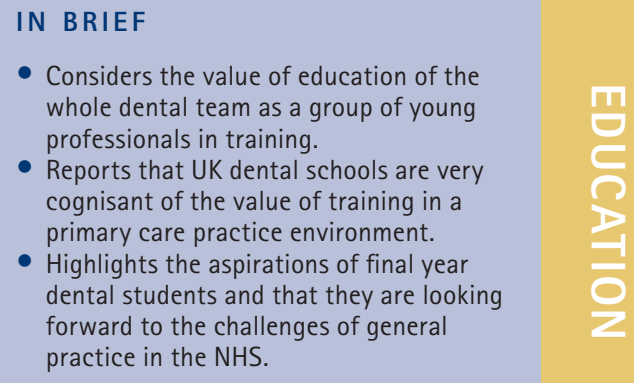

\author{
D. R. Radford, ${ }^{* 1}$ S. Holmes, ${ }^{2}$ M. J. Woolford ${ }^{3}$ and S. M. Dunne ${ }^{4}$
}

Objective To investigate the responses of the dental student body in the first three years of outreach education (2010-13) at the University of Portsmouth Dental Academy in the areas of integrated team work and use of a current NHS contact. Methods Use of a questionnaire to allow both quantitative and qualitative data to be obtained, administered to the three cohorts of students at the end of their longitudinal attendance at the Academy in their final year of education at King's College London Dental Institute. Results Data were obtained from 227 students which represented a 95\% return rate. Sixty-four percent of students strongly agreed with both statements: 'I am confident with working with a dental nurse' and 'I now understand properly the scope of practice of dental hygiene-therapists'. Sixty-seven percent strongly agreed with the statement 'I have had useful experience of working in NHS primary care during the final year'. Eighty percent either strongly agreed or agreed with the statement 'My experience of real Units of Dental Activity and Key Performance Indicators has encouraged me to positively consider NHS high street dentistry as a career option'. Conclusions Within the limitations of this study the dental students reported having gained useful experience of working in integrated team care dentistry. They expressed strong support for the education that is being delivered in an outreach environment and, most importantly, the student body was looking forward to entering general dental practice in the UK.

\section{INTRODUCTION}

There are numerous reports in the literature on the value of dental outreach education (community-based clinical dental education) and how it has been embraced as an intrinsic part of the undergraduate curriculum. ${ }^{1-5}$ Different schools have a range of alternative approaches to outreach training, either being delivered in purpose-built facilities or a dispersed model of using a number of existing practices. In some schools it is 'discipline specific' while others expose their students to total patient care. The timing of students' participation in outreach is diverse in terms of both years at dental school and whether the experience is delivered in a block or linear fashion.

\footnotetext{
Senior Lecturer in Integrated Dental Education and Multi-Professional Care, King's College London Dental Institute and University of Portsmouth Dental Academy; ${ }^{2}$ Professor of Dental Education, Director of the University of Portsmouth Dental Academy; ${ }^{3}$ Professor and Associate Dean (Education), King's College London Dental Institute; ${ }^{4}$ Professor of Primary Dental Care, King's College London Dental Institute ${ }^{*}$ Correspondence to: David R. Radford Email: david.radford@kcl.ac.uk
}

\section{Refereed Paper}

Accepted 22 July 2014

DOI: 10.1038/sj.bdj.2014.1002

${ }^{\circledR}$ British Dental Journal 2014; 217: 581-585
As the establishment of the University of Portsmouth Dental Academy (UPDA) was a development of the highly successful School of Professionals Complementary to Dentistry of the University of Portsmouth, it has an over-arching philosophy of integrated dental education and multiprofessional care (Table 1, adapted from Smith et al. ${ }^{7}$ ). As reported by Lynch et al. (2013), ${ }^{6}$ ten UK dental schools teach integration with student dental therapists, seven with student dental hygienists and four with student dental nurses. From the inception of the UPDA, all treatment was undertaken as integrated teams of young professionals in training that is, dental, dental hygiene-therapy and dental nursing students. ${ }^{8}$

The UPDA, as previously reported, ${ }^{9,10}$ operates to a Personal Dental Service (PDS) Plus contract, which was commissioned formerly by the local Primary Care Trust and currently Wessex Area Team, with students providing appropriate care against a background of this system of remuneration. This type of contract is common for the provision of NHS dental services in primary care in England. Students attend from King's College London Dental Institute (KCLDI) in a linear fashion over their Final Year, one residential week in four (ten weeks in total). The scope of practice is total patient care within the NHS contract, as well as a community outreach away from the UPDA. ${ }^{11}$ Utilising a live NHS contract exposes the students to the reality of having a personal UDA (Unit of Dental Activity) target and of completing and recording of both national and local Key Performance Indicators (KPIs). Part of the contract is also to see emergency patients who are not currently receiving care at the UPDA who have contacted the local NHS dental helpline on the day. The philosophy of this training is not just to ease their transition into Dental Foundation Training (DFT), but to allow them to experience NHS primary care, its administration, computerised notes with a direct contact to the British Services Authority (BSA) and treatment planning in a staged approach in order to establish dental health.

The reliance on an NHS contact is not a universal feature of outreach education in the UK. Lynch et al. $(2013)^{6}$ reported that of the 14 schools in the UK and Ireland that responded to a questionnaire, nine schools indicated that completion of UDAs was not a concern for their programme or funding, whereas two schools (including KCLDI) 
stated it was of importance. The aim therefore of this research, which is part of a larger comprehensive teaching evaluation, was to explore how this experience in integrated team working using a live NHS contract would influence the thinking of the students as to how they would progress their early career post-dental foundation training.

\section{METHODS}

The study was devised as a service evaluation of outreach education at the Academy. Three student cohorts, 80 students in each year cohort, were asked to complete a 49 item questionnaire divided into nine domains that provided both quantitative and qualitative data. The questionnaire was developed from the intended learning outcomes (Table 1) and was modified after discussion with clinical teachers involved with the students' clinical education. The questionnaire was completed anonymously in their last week of attendance just before qualification. The domains are listed below:

- Domain 1: support and communication

- Domain 2: induction programme

- Domain 3: course book

- Domain 4: your clinical experience

- Domain 5: tutorials

- Domain 6: team experience and integrated care

- Domain 7: NHS dentistry

- Domain 8: DFT job applications

- Domain 9: accommodation and social.

The quantitative data was handled with descriptive statistics with the qualitative data (free text responses) analysed for recurring themes that supported the findings of the numerical data. For the purpose of this part of the study, Domains 6 and 7, which consisted of 13 questions on team experience and NHS dentistry, are reported. Other domains are subject of a separate publication.

\section{RESULTS}

Data were obtained from 227 students, which represented a 95\% return rate. The results are presented as quantitative data with selected free text comments.

\section{Domain 6: team experience and integrated care}

\section{Working with nursing support at chairside}

From Table 2, 64\% of students strongly agreed with the statement 'I am now confident with working with a dental nurse'. The theme of the free text comments are centred round the value of working with close support, as well as the enjoyment in teaching the student dental nurses.

Table 1 Intended learning outcomes (ILOs) from education at the University of Portsmouth Dental Academy and the specific outcomes relevant to this aspect of the service evaluation are highlighted (italics)

\section{Personal development}

\begin{tabular}{l|l}
\hline Aim & $\begin{array}{l}\text { To encourage students' progress towards professional working, particularly DFT } \\
\text { To increase students' confidence in the clinical environment. }\end{array}$ \\
\hline ILO & $\begin{array}{l}\text { In particular students should have: } \\
\text { Developed greater independence in decision making. } \\
\text { An increased awareness of interactions within the dental team and between the team } \\
\text { and other agencies. } \\
\text { Experience working as a dental student and life at a university and city outside London. } \\
\text { Presented their patients systematically including proposing holistic care plans and } \\
\text { alternatives. } \\
\text { Where appropriate, completed courses of treatment in conjunction with the } \\
\text { dental teams and evaluated both outcomes and the team's performance. } \\
\text { Summarised their learning experiences on completion of the programme and discussed } \\
\text { them with their tutor/tutors. }\end{array}$
\end{tabular}

Professional responsibility

\begin{tabular}{l|l}
\hline Aim & $\begin{array}{l}\text { To encourage students to appreciate the ethical responsibility of dental professionals } \\
\text { for the oral health and optimal clinical care for the whole community. }\end{array}$ \\
\hline ILO & In particular students should have: \\
& An awareness of the changing needs and expectations of the community. \\
& An awareness of the dental professions wider role within primary care. \\
& An awareness of links with other services within and out-with health services. \\
& An awareness of the overriding responsibility to protect and promote general health.
\end{tabular}

Practice environment

\begin{tabular}{|c|c|}
\hline Aim & $\begin{array}{l}\text { To encourage students to appreciate the responsibilities and requirements of the prac- } \\
\text { tice environment within the primary care setting. }\end{array}$ \\
\hline ILO & $\begin{array}{l}\text { Specifically students should have: } \\
\text { Gained an appreciation of the organisation of the clinical environment, including } \\
\text { health and safety aspects. } \\
\text { Appreciated the need for time management and setting priorities with regard to the } \\
\text { planning of patient care particularly using the skills and knowledge of the dental } \\
\text { team. } \\
\text { Appreciated the role of clinical governance and its application in the primary care } \\
\text { practice environment. } \\
\text { Appreciated the importance of teamwork within the expanded dental team. } \\
\text { Educated the students in how to lead and be a resource to the dental team. } \\
\text { Experienced use of a practice based compute based record keeping system. } \\
\text { Gained some insight into successful business management in dental practice. }\end{array}$ \\
\hline \multicolumn{2}{|c|}{ Further developments of clinical skills } \\
\hline Aim & $\begin{array}{l}\text { To consolidate awareness and develop students' skills in the provision of comprehensive } \\
\text { oral care for a range of patient groups, including the 'hard to reach'. }\end{array}$ \\
\hline ILO & $\begin{array}{l}\text { In particular students should have: } \\
\text { Developed the skills of patient management, including communication skills. } \\
\text { Developed the skills of diagnosis and holistic team care treatment planning. } \\
\text { Experienced and gained skills in team dentistry. } \\
\text { Experienced and gained skills in referral of prescribed treatment between team } \\
\text { members. } \\
\text { Developed skills in the use of preventative dentistry techniques in the 'hard to reach' } \\
\text { patient. } \\
\text { Further developed the skills of clinical operative dentistry in primary dental care } \\
\text { environments. }\end{array}$ \\
\hline
\end{tabular}

Comments included:

- 'Most of the nursing support I have had here has been of excellent quality - really encompassed the meaning of 'fourhanded dentistry"

- 'Enjoyed working with qualified dental nurses - also helped me to become more confident taking radiographs'

- 'Working with the qualified nurses was excellent and it is amazing how much faster and easier treatment is with them' - 'I enjoyed working with the nursing students in particular and especially the new students and helping them set up and explaining why I am doing what I am doing.'

\section{Working with dental hygiene therapy (DHT) students}

To the statement: 'I now understand properly the scope of practice of Dental Hygiene and Therapy', 64\% strongly agreed (Table 2). The free text comments reinforced the quantitative findings as how valuable working with 


\begin{tabular}{|c|c|c|c|c|c|c|}
\hline \multicolumn{7}{|l|}{ Table 2} \\
\hline Statement & $\begin{array}{l}\text { Strongly } \\
\text { agreed } \%\end{array}$ & $\begin{array}{l}\text { Agreed } \\
\%\end{array}$ & $\begin{array}{l}\text { Neutral } \\
\%\end{array}$ & $\begin{array}{l}\text { Disagreed } \\
\%\end{array}$ & $\begin{array}{l}\text { Strongly } \\
\text { disagreed \% }\end{array}$ & $\begin{array}{l}\text { N/A } \\
\%\end{array}$ \\
\hline $\begin{array}{l}\text { I am now confident with } \\
\text { working with a dental nurse }\end{array}$ & 64 & 32 & 3 & 1 & 0 & 0 \\
\hline $\begin{array}{l}\text { I now understand properly the } \\
\text { scope of practice of Dental } \\
\text { hygiene and therapy }\end{array}$ & 64 & 34 & 2 & 0 & 0 & 0 \\
\hline $\begin{array}{l}\text { After Vocational training I would } \\
\text { actively try to find a practice } \\
\text { employing a dental therapist }\end{array}$ & 46 & 38 & 14 & 2 & 0 & 0 \\
\hline
\end{tabular}

\begin{tabular}{|c|c|c|c|c|c|c|}
\hline Statement & $\begin{array}{l}\text { Strongly } \\
\text { agreed \% }\end{array}$ & $\begin{array}{l}\text { Agreed } \\
\%\end{array}$ & $\begin{array}{l}\text { Neutral } \\
\%\end{array}$ & $\begin{array}{l}\text { Disagreed } \\
\%\end{array}$ & $\begin{array}{l}\text { Strongly } \\
\text { disagreed } \%\end{array}$ & $\begin{array}{l}\mathrm{N} / \mathrm{A} \\
\%\end{array}$ \\
\hline $\begin{array}{l}\text { Through my Portsmouth } \\
\text { experience I feel well prepared } \\
\text { for qualification and DFT }\end{array}$ & 64 & 30 & 5 & 0 & 0 & 1 \\
\hline $\begin{array}{l}\text { I have had useful experience in } \\
\text { working in NHS primary care } \\
\text { during the final year }\end{array}$ & 67 & 29 & 3 & 0 & 0 & 1 \\
\hline $\begin{array}{l}\text { The 'Portsmouth experience' } \\
\text { has prepared me well for } \\
\text { clinical NHS dentistry }\end{array}$ & 64 & 31 & 3 & 1 & 0 & 1 \\
\hline
\end{tabular}

\begin{tabular}{|c|c|c|c|c|c|c|}
\hline Statement & $\begin{array}{l}\text { Strongly } \\
\text { agreed } \%\end{array}$ & $\begin{array}{l}\text { Agreed } \\
\%\end{array}$ & $\begin{array}{l}\text { Neutral } \\
\%\end{array}$ & $\begin{array}{l}\text { Disagreed } \\
\%\end{array}$ & $\begin{array}{l}\text { Strongly } \\
\text { disagreed \% }\end{array}$ & $\begin{array}{l}\text { N/A } \\
\%\end{array}$ \\
\hline $\begin{array}{l}\text { I now understand the role a } \\
\text { dentist has in primary care with } \\
\text { regard to treatment planning }\end{array}$ & 68 & 29 & 2 & 0 & 0 & 1 \\
\hline $\begin{array}{l}\text { The Portsmouth experience has } \\
\text { prepared me well for the paper } \\
\text { work (governance issues) in } \\
\text { NHS dentistry }\end{array}$ & 58 & 38 & 4 & 0 & 0 & 0 \\
\hline
\end{tabular}

DHT students has proven to be and how the dental students felt they now understood the full scope of practice of these colleagues.

Comments included:

- 'Before coming here, I had never referred patients to DHT and did not know how to. Now it's routine'

- 'Enables understanding of multidisciplinary care with referral system to DHT students'

- 'Before coming to UPDA, I had a limited understanding of the scope of practice of other members of the dental team. I found working with the DHT very valuable and enjoyable and I feel much more confident prescribing to them.'

\section{Impact on future practice support}

To the statement: 'After vocational training (VT) I would actively try to find a practice employing a dental therapist' 46\% strongly agreed, 38\% agreed (Table 2). The free text comments reflected the value that students perceive with working with DHT students and working within a team, however, this would be an added advantage in practice after strongly agreed; 'I have had useful experience in working in NHS primary care during the final year', 67\% strongly agreed; and 'The 'Portsmouth Experience' has prepared me well for clinical NHS dentistry', 64\% strongly and 31\% agreed. The themes that were identified in the free text comments centred on increasing confidence, wider and more proficient skills and a greater awareness of primary care dentistry. However, some students tempered their enthusiasm with comments about only being able to tell how well prepared they were once qualified and working in practice.

Comments included:

- 'True experience of dental care setting outside London'

- 'UPDA gave me valuable training in a primary care setting and a realistic working approach'

- 'A lot more experience managing a team here and independence to improve confidence'

- 'I now feel prepared for working alone with minimal tutor impact. My confidence has grown immensely as a result of Portsmouth'

- 'Excellent bridge between dental school and VT. Very useful skills picked up especially treatment planning, radiograph taking and becoming faster with treatment'

- 'It definitely enhanced my understanding of the UDA system, its limitations and the importance of patient education to have better oral health and how important it is to deliver better oral health'

ocational training rather than a priority.

Comments included:

- 'DHT's are essential'

- 'Team working has prepared me for practice and I appreciate the valuable role of DCPs'

- 'I wouldn't actively search for a job based on a therapist being there, but it would certainly be a bonus'

- 'I have very much enjoyed working as part of a team, however I am unsure as to whether I would actively seek out a practice employing therapists'

- 'After VT, it would be nice to work with therapists, but would not be my primary concern, as location, equipment, nursing would.'

\section{Domain 7: NHS dentistry}

Domain 7 was divided into three intended learning outcomes.

\section{General dental experience}

To the three statements (Table 3): 'Through my Portsmouth experience I feel well prepared for qualification and DFT', 64\%
- 'Difficult to comment on how well prepared until we start working but the NHS contract is changing again'

- 'It is difficult to say how beneficial it has been until we finish DFT and have experienced NHS dentistry, but as things stand I feel very confident post-graduation.'

\section{Specific primary care statements}

The response to the two statements (Table 4): 'I now understand the role a dentist has in primary care with regard to treatment planning', 68\% strongly agreed; and 'The Portsmouth experience has prepared me well for the paper work (governance issues) in NHS dentistry' either 58\% strongly agreed or $38 \%$ agreed.

Free text comments focused on governance issues and treatment planning in primary care using a current NHS contract.

Comments included

- 'Better idea of care, clinical governance pathways, audits, recall intervals, referrals and importance of note keeping' 
- 'Portsmouth experience has made me appreciate UDAs KPIs and working in multi-disciplinary team but not really how a NHS practice may run or how to offer cost effective treatments as patients still aren't paying for treatment here. But on the whole I think I have improved on planning treatment and thinking more when offering treatment on an NHS plan

- 'Feel more confident using computer systems and NHS dentistry in general'

- 'In hindsight, if I did not attend Portsmouth I know I would have huge difficulties in transitioning to NHS work. UDAs and KPIs and clinical governance are vital aspects of NHS work. We see more patients here and there is a real sense of teamwork and community with patients and staff.

- 'Opened my eyes to realistic planning and staging treatment for complex patients'

- 'I have learnt and used a RAG risk rating that I believe will be in the new contr act so good for the future'

- 'I felt we treat the patient as a whole in Portsmouth. Also here we are more realistic in terms of what treatment the patient really needs rather than just focusing on quotas.'

\section{Attitudes to working in NHS practice}

Five statements in this area were presented, as this is the major area of difference between working in primary care $v s$ a dental school (Table 5). This theme also explored specifically students' confidence in the use of a current NHS contract and their concerns of working in NHS post qualification.

Themes identified from the free text comments included the aspect that working to UDAs and KPIs was difficult with patients with a high treatment need. However, this experience had not put students off the prospect of providing NHS high street care.

Comments included:

- 'There is no doubt that I am better prepared to cope with the primary dental care system in DFT now than if I had stayed in London. I don't believe KPIs or UDAs are the best way of determining fees, but I'm not sure what would be'

- 'UDA system I would not consider a fair remuneration system and has not solved the problems of patient understanding. Hopefully capitation will prove to be the most ethical way of paying dentists'

- 'UDAs quite frankly are terrible. It squeezes the care to a minimum. I've learnt a lot from this experience, and hopefully a lot of it will come in handy for the year to come'

\begin{tabular}{|c|c|c|c|c|c|c|}
\hline Statement & $\begin{array}{l}\text { Strongly } \\
\text { agreed } \%\end{array}$ & $\begin{array}{l}\text { Agreed } \\
\%\end{array}$ & $\begin{array}{l}\text { Neutral } \\
\%\end{array}$ & $\begin{array}{l}\text { Disagreed } \\
\%\end{array}$ & $\begin{array}{l}\text { Strongly } \\
\text { disagreed \% }\end{array}$ & $\begin{array}{l}\mathrm{N} / \mathrm{A} \\
\%\end{array}$ \\
\hline $\begin{array}{l}\text { I gained valuable experience of } \\
\text { the current system of UDAs }\end{array}$ & 64 & 32 & 2 & 1 & 0 & 1 \\
\hline $\begin{array}{l}\text { UDAs are a fair system for } \\
\text { remuneration of primary care }\end{array}$ & 13 & 16 & 22 & 31 & 17 & 1 \\
\hline $\begin{array}{l}\text { My experience of an NHS Plus } \\
\text { contract has made me more } \\
\text { fearful of my DFT year }\end{array}$ & 6 & 16 & 26 & 33 & 16 & 3 \\
\hline $\begin{array}{l}\text { My experience of real UDAs and } \\
\text { KPIs has encouraged me to posi- } \\
\text { tively consider NHS high street } \\
\text { dentistry as a career option. }\end{array}$ & 50 & 30 & 13 & 6 & 0 & 1 \\
\hline $\begin{array}{l}\text { I am looking forward to } \\
\text { working in NHS primary } \\
\text { dental care in the future }\end{array}$ & 43 & 39 & 14 & 1 & 2 & 1 \\
\hline
\end{tabular}

- 'Three UDAs for four RCT and six restorations and one patient'

- 'Having the same UDAs for XLA and restorations is not fair'

- 'Now I want to be a GDP thanks to UPDA'

- 'Before coming to Portsmouth I was adamant that I did not want to be a GDP but after being at UPDA I have now changed my mind.'

\section{DISCUSSION}

This study focuses on just two of the domains that have been part of the final evaluation of the student's experience of outreach education delivered in Portsmouth over a three year period (2010-13). The rational for reporting these separately from the other seven domains of the overall evaluation is to investigate the impact of integrated team care dentistry using a current NHS contact during the final year of the dental students education. The other seven domains investigated aspects of the 'Portsmouth experience' such as the quality of clinical education and the residential aspect of outreach and this will be reported subsequently.

The results clearly showed that the students did not just value working as part of the integrated dental team but recognised the value of working with qualified dental nurses and dental nursing and dental hygiene-therapy students. This is a key element of the GDC Guidance 'Students Fitness To Practice' in terms of 'cooperating with other members of the dental team and other healthcare colleagues in the interests of patients.12 Despite this, they did not describe working with a hygiene-therapist, post DFT, as an overriding priority, with only $46 \%$ strongly agreeing with the statement: 'I would actively try to find a practice employing a dental therapist'. However, the educational aspiration of encouraging the students to work and learn together as teams of young professionals in training was fully endorsed as they were able to experience working effectively as part of a team, understanding the roles and responsibilities of others but more importantly respecting the skills and contribution of their colleagues..$^{12} \mathrm{On}$ a practical note, the true integration of learning as a group of dental professionals in training is difficult to coordinate. This is partly as the final year dental students are only in Portsmouth for one week in four and immerse themselves in clinical dentistry, whereas the second and third year DHT students (Level 5, 6, BSc Honours Programme) are undertaking clinical practice in association with formal didactic education. In addition, the overall timetable for the year, including activities such as assessment periods, differed between the University of Portsmouth and King's College London. However, to ensure, improve and encourage clinical integration the students had joint practice team meetings at the start of the week, undertook joint treatment planning and accessed confidential internal messaging via the computerised clinical records.

The results from the students' responses to the use of a current and live NHS contact within an educational model are very encouraging. Introducing the contract during their final year, but when still in education at undergraduate level, allows students to understand how to provide ethical treatment for a large range of patients, from those with high treatment needs to those requiring maintenance. Further, the positive response to their future careers as general dental practitioners is encouraging as certainly the transition into foundation training as 'safe beginners' is made easier as they have learnt and understood the rules relating to the current contract and used a computerised note system linked to the British Services Authority that is widely used in primary care dentistry. This was highlighted by over $80 \%$ of the cohort either strongly agreeing or agreeing with the 
statement: 'My experience of real UDAs and KPIs has encouraged me to positively consider NHS high street dentistry as a career option' Furthermore, over 53\% strongly disagreed or disagreed with the statement: 'My experience of a PDS Plus NHS contact has made me more fearful for my DFT year'. However, like many in the profession, they did not consider the current system a fair basis for remuneration of primary care, which is reflected in the free text comments 'Three UDAs for four RCT and six restorations and one patient'.

In terms of the outcomes of the education fulfilling the set intended learning outcomes of the educational programme the majority of these have been met (Table 1). One outcome, although not directly tested by the questionnaire, which is probably not being fully met is 'I gained some insight into successful business management in dental practice'. It is important to view outreach education as giving the students some insight into practice rather than replicating Dental Foundation Training. However, like others, ${ }^{13}$ this deficiency has been highlighted by King's College London Dental Institute Alumni and as a consequence a longitudinal course teaching some of these skills have been adopted by the new curriculum being delivered in London.

\section{CONCLUSION}

Within the limitations of this evaluation the dental students reported to have gained useful experience of working in integrated team care dentistry, with them expressing support for the education that is being delivered in outreach education and more importantly the student body looking forward to entering NHS general dental practice in the UK.

The authors would like to acknowledge the help of Gemma Potts in helping to prepare the questionnaire and collating the results. We also acknowledge the clinical tutors of the Academy for their contribution in the delivery of integrated dental education to the students.

1. Smith M A, Lennon A, Brook A H, Ritucci L, Robinson P G. Students perspectives on their recent dental outreach placement experiences. Eur J Dent Educ 2005; 10: 80-86.

2. Elkind A, Watts C, Qualtrough A et al. The use of Outreach clinics for the teaching undergraduates restorative dentistry. Br Dent J 2007; 203: 127-132.

3. Craddock H L Outreach teaching -the Leeds experience: reflections after one year. Br Dent J 2008; 204: 319-324.

4. Davis B R, Leung A N, Dunne S M. Perceptions of a simulated general dental practice facility - reported experiences from past students at the Mauice Whol
General Dental Practice Centre 2001-2008. Br Dent J 2009; 207: 371-376.

5. Lynch C D, Ash P J, Chadwick B L. Students perspectives and opinions on their experience at an undergraduate outreach dental teaching centre at Cardiff: a 5 year Study. Eur J Dent Educ 2010; 14: 12-16.

6. Lynch C D, Ash P J, Chadwick B L. Current trends in community-based clinical teaching programs in U K, Ireland dental schools. J Dent Educ 2013; 77: 604-611.

7. Smith $M$, Ash P, Gilmour A S M, Austin T, Robinson $P$ G. Outreach training: the special interest group's report. Eur J Dent Educ 2011; 15: 85-89.

8. Wanyonyi K L, Radford D R, Gallagher J E. The relationship between access to and use of dental services following expansion of a primary care service to embrace dental team education. Public Health 2013; 127: 1028-1033.

9. Radford D R. A personal perspective, breaking new ground in Portsmouth in integrated dental education and professional care. 2011. Online information available at http://www.kcl.ac.uk/study/ earningteaching/kli/research/hern/hernjvol2.pdf (accessed 28 October 2014).

10. Radford D R, Woolford M, Dunne A M, Holmes S. Better prepared. Br Dent J 2012; 213: 47.

11. Radford D R, Weld J A. Micro-educational opportunities in outreach clinical dental education. Br Dent J 2013; 215: 389-391.

12. General Dental Council. Student fitness to practise. 2010. Online information available at http://www. gdc-uk.org/Newsandpublications/Publications/ Publications/StudentFtPApril10web_260310[1].pdf (accessed 28 October 2014).

13. Morrison S, McMullan C. Preparing for the future: challenges and opportunities for management and leadership skills. Br Dent J 2013; 214: E2.

\section{Erratum}

Practice (BDJ 2014; 217: 357-362)

Preventing wrong tooth extraction: experience in development and implementation of an outpatient safety checklist

The authors' affiliation section was incomplete in the original paper. It should have read as follows;

\section{A. Saksena, ${ }^{* 1}$ M. N. Pemberton, ${ }^{2}$ A. Shaw ${ }_{1}^{3}$ S. Dickson ${ }^{4}$ and M. P. Ashley ${ }^{5}$}

${ }^{1}$ Consultant in Oral Surgery, Clinical Effectiveness Lead in Oral Surgery, ${ }^{2}$ Consultant in Oral Medicine, Clinical Head of Division, ${ }^{3} \mathrm{Clinical}$ Effectiveness Manager, ${ }^{4}$ Divisional Director, ${ }^{5}$ Consultant in Restorative Dentistry, Associate Clinical Head of Division, University Dental Hospital of Manchester, Higher Cambridge Street, Manchester, M15 6FH ${ }^{*}$ Correspondence to: A. Saksena

E-mail: alka.saksena@cmft.nhs.uk 